\title{
Avaliação da Liquidez das Empresas Através da Análise da Demonstração de Fluxos de Caixa
}

\author{
Roberto Braga \\ Professor Doutor do Departamento de \\ Contabilidade e Atuária da FEA/USP e pesquisador \\ da FIPECAFI.
}

\author{
José Augusto Veiga da Costa Marques \\ Pós-doutorado no Departamento de \\ Contabilidade e Atuária da FEA/USP e \\ professor da FACC/UFRJ.
}

RESUMO

Dentre as principais alterações previstas na legislação societária inclui-se a substituição da demonstração das origens e aplicações de recursos pela demonstração de fluxos de caixa (DFC), que apresentam finalidades até certo ponto distintas. Apenas divulgada no país por algumas raras companhias, a DFC permanece pouco explorada no tocante a seu formato de exposição por categorias de atividades, seus métodos de elaboração do fluxo de caixa gerado pelas operações e, principalmente, sua utilização para fins de análise da liquidez das organizações. A utilização de quocientes extraídos de relações entre valores da DFC facilita a interpretação da situação financeira da empresa, sendo o fluxo de caixa operacional a medida absoluta mais relevante mostrada no relatório. Esses índices foram classificados em quatro categorias distintas, cujos propósitos variam da avaliação da capacidade de pagamento do negócio até a determinação das taxas de recuperação (retorno) de caixa. De modo a demonstrar a viabilidade da análise financeira com base na DFC, foram calculados e interpretados os quocientes extraídos dos relatórios publicados pelas empresas - Companhia Vale do Rio Doce (CVRD) e Centrais Elétricas de Minas Gerais S/A (CEMIG), para dois anos consecutivos. Por fim, foram expostas algumas linhas de pesquisa, e ressaltada a questão inerente à classificação dos fluxos de caixa entre as atividades operacionais, de financiamento e de investimento, um problema que os órgãos normativos terão de enfrentar em momento próximo.

Palavras-chave: demonstração de fluxos de caixa; liquidez e solvência; taxas de recuperação de caixa; avaliação do desempenho; formato por atividades; critério de classificação.
ABSTRACT

Among the various changes expected in the upcoming version of the Brazilian corporate law, the substitution of the statement of changes in financial position by the cash flow statement (CFS) stands as one of the most impacting innovations. The CFS is published by few companies in the country and its format, its potential as an instrument for liquidity analysis, as well as possible methods of deriving operating cash flow from it have not been sufficiently explored in the existent literature. The authors propose that the use of ratios obtained from items of the CFS lead to data about financial liquidity, since the operating cash flow is the most important measure of the statement. This study classifies the ratios into four different categories whose purposes vary from determining the business debt payment capacity to the cash return rate. In order to test the CFS financial analysis validity, the authors applied the proposed method to data extracted from CVRD and CEMig reports. Finally, before presenting ideas for future work, this study discusses the issue of classifying cash flow into operating, financing, and investing categories, a problem that accounting committees will face soon.

Key words: cash flow statement; liquidity and solvency; cash return rate; performance valuation; activity format; classification criteria. 


\section{INTRODUÇÃO}

\section{Aspectos Introdutórios}

As mudanças implementadas no ambiente econômico nacional certamente contribuirão para o desenvolvimento de novos padrões de comportamento e gestão pelos administradores das empresas. Em especial, as prenunciadas alterações da atual legislação societária (Lei 6.404 de 1976) visam, sobretudo, à melhoria da qualidade informativa dos relatórios contábeis transmitidos ao mercado. Um dos pontos mais polêmicos destas alterações diz respeito à substituição da demonstração das origens $e$ aplicações de recursos - um relatório reconhecidamente mais rico e completo em informações econômicas, mas de difícil compreensão pelos usuários menos especializados - pela demonstração de fluxos de caixa - não considerada tão completa quanto a primeira, mas de interpretação bem mais simples e objetiva.

Embora ainda não publicada em termos regulares e/ou conhecida de forma completa pela maior parte dos investidores brasileiros, a demonstração de fluxos de caixa (DFC) possui como uma de suas finalidades servir de instrumento para avaliação da liquidez da organização, ou seja, sua capacidade e garantia de pagamento das dívidas nas datas de vencimento.

Nesse aspecto, inúmeras medidas de desempenho podem ser obtidas a partir da DFC, notadamente aquelas que relacionam o fluxo de caixa gerado (ou consumido) pelas atividades operacionais normais da companhia (FCO) a algum item específico. Há a possibilidade de classificá-las de diferentes maneiras como, por exemplo, para avaliar o grau de suficiência ou eficiência do negócio, ou ainda para medir a capacidade de pagamento ou o nível de retorno associado a um determinado elemento patrimonial.

Uma das relações mais atraentes da análise financeira da DFC consiste na taxa de recuperação (ou retorno) de caixa, a qual resulta da divisão entre o FCO e o ativo total, ativo operacional ou patrimônio líquido, a exemplo de sua análoga numa base de registro por regime de competência: a taxa de retorno contábil.
Nesse sentido, este estudo procura expor significados e formas de utilização de alguns daqueles quocientes, sempre no sentido de valorizá-los em comparação àqueles outros obtidos a partir do balanço patrimonial de idênticos propósitos. Além disso, enfatiza-se sua complementariedade no tocante aos indicadores convencionais de estrutura, lucratividade e retorno. Em face da iminente alteração da norma legal, este estudo apresenta algumas alternativas de análise ao investidor, especialmente em suas avaliações de solvência das empresas. De modo a permitir uma melhor compreensão do assunto, serão calculadas e interpretadas algumas medidas extraídas com base nas DFCs publicadas pela Cia. Vale do Rio Doce e pelas Centrais Elétricas de Minas Gerais S/A para os exercícios findos em 31 de dezembro de 1997, 1998 e 1999, uma vez que essas companhias divulgaram a demonstração junto a seus relatórios anuais. Contudo, o estudo não pretende aprofundar outros aspectos da análise financeira que não o da liquidez.

\section{A Demonstração no Contexto da Nova Legislação Societária}

Muitos avanços foram notados no anteprojeto da nova legislação societária, que introduz um conjunto de mudanças nas práticas atuais de divulgação. Um desses avanços consiste na futura obrigatoriedade de publicação das demonstrações de fluxos de caixa e do valor adicionado pelas sociedades por ações. Conforme menciona o referido anteprojeto:

"As demonstrações referidas nos (...) indicarão, no mínimo

I - a demonstração dos fluxos de caixa - as alterações ocorridas no exercício no saldo de caixa e equivalentes de caixa, segregadas em fluxos das operações, dos financiamentos e dos investimentos.

II - a demonstração do valor adicionado - os componentes geradores do valor adicionado e a sua distribuição entre empregados, financiadores, acionistas, governo e outros, bem como a parcela retida para reinvestimento." 
A obrigatoriedade de apresentação dos dois relatórios - o primeiro em substituição à demonstração das origens e aplicações de recursos - nasceu, de certo modo, das crescentes necessidades informativas dos usuários, cada vez mais interessados na capacidade de geração de caixa das empresas. De modo a obterem recursos pela emissão de ações, debêntures e ADRs nos Estados Unidos e Europa, as companhias se comprometiam a prestar informações adicionais, em conformidade com as normas de divulgação do país da emissão. A DFC, sem dúvida, passou a ser publicada de forma espontânea por algumas sociedades, uma vez que já prestavam essa informação naqueles mercados em que captavam recursos. Contudo, além de representarem ainda um número reduzido de empresas, existem dificuldades em conseguir essas e outras informações, obrigatórias em outros mercados e apenas "encorajadas" para divulgação no Brasil. Raras são as companhias que aqui apresentam alguma informação adicional sobre seus fluxos de caixa durante o exercício social ${ }^{1}$.

\section{A Demonstração sob as Normas de Divulgação do FASB}

Os Estados Unidos da América constituem, sem dúvida, a melhor referência no desenvolvimento de pesquisas e divulgação a respeito da DFC. A DFC passou a ser exigida das empresas norteamericanas em 1987, com a emissão do Statement of Financial Accounting Standards No. 95 Statement of Cash Flows ${ }^{2}$ (SFAS No. 95). Após esse momento surgiram alterações introduzidas por meio de instruções subsequentes ${ }^{3}$, porém restritas à classificação de transações e eventos específicos. Além disso, outros países anglo-saxônicos seguiram a iniciativa do Financial Accounting Standards Board (FASB) e instituíram também a obrigatoriedade dessa demonstração, como Canadá, Reino Unido e Irlanda do Norte, Austrália, Nova Zelândia e África do $\mathrm{Sul}^{4}$, cada qual com pequenas diferenças relativas.

O SFAS No. 95 determinou os procedimentos e critérios de exposição da DFC, com a adoção de um formato por atividades. Dentre os principais aspectos da norma listam-se os seguintes:

- Para fins de elaboração da demonstração, "caixa" inclui dinheiro em mãos, contas bancárias não vinculadas e aplicações financeiras adquiridas até três meses antes do vencimento (cash and nearcash items). Títulos mantidos pela empresa quando de três meses do resgate não são incluídos, somente os adquiridos até esse prazo limite;

- O relatório deve ser exposto por fluxos de atividades. As atividades operacionais, de financiamento e de investimento foram, até certo ponto, objetivamente definidas, embora não houvesse surgido consenso entre os membros do FASB no momento de emissão da norma;

- O somatório dos fluxos das atividades, adicionado ao saldo inicial de caixa mostrado no balanço patrimonial (disponibilidades), deriva seu saldo ao final do período;

- As transações e eventos que não afetam o caixa no momento presente, mas que significam atividades de financiamento e investimento, devem ser expostos em notas explicativas de modo a permitir aos usuários avaliações de fluxos futuros de caixa. Por exemplo, o arrendamento mercantil de equipamentos industriais não afeta o fluxo atual de caixa, todavia certamente implicará em saídas futuras de caixa devido aos pagamentos do principal e juros da dívida;

- Foi encorajada a adoção do método direto para derivação do fluxo de caixa das atividades operacionais, sendo porém permitido o método indireto. Esse último parte do resultado líquido (demonstração de resultado) até chegar ao caixa operacional, depois de efetuar ajustes para eliminação de resultados que não afetaram o caixa mas que se acham incluídos no lucro e, também,

\footnotetext{
${ }^{1}$ Algumas companhias têm adotado o formato de exposição conforme as normas do Instituto Brasileiro de Contadores - IBRACON, com base na NPC 20 emitida em abril de 1999. Por sua vez, outras têm preferido o formato exigido pelas normas norte-americanas.

2 Statement of Accounting Financial Standards No. 95. Statement of Cash Flows. Financial Accounting Series. Financial Accounting Standards Board of the Financial Accounting Foundation, november, 1987.

3 SFAS Ns. 102, 104 e 117.

${ }^{4}$ WAllaCE, R. S. \& COLliER, P. A .. The 'Cash' in Cash Flow Statements: A Multi-Country Comparison. Accounting Horizons, december, 1991
} 
das variações de ativos e passivos operacionais. Também não houve consenso no tocante a esse aspecto.

\section{Formato de Divulgação por Atividades}

O formato de apresentação da DFC mais difundido - até por motivos legais - tem sido aquele por atividades, que contempla as atividades operacionais, de financiamento e de investimento (Figura 1). As atividades de financiamento se acham relacionadas à estrutura de financiamento da empresa e envolvem as modificações nos exigíveis de curto e longo prazos e no patrimônio líquido, que afetam o caixa, exceto aquelas associadas às operações. De acordo com o SFAS No. 95, parágrafos 18 a 20, tem-se que:

Figura 1: Classificação das transações que envolvem caixa por atividades

Fluxo de caixa das atividades de investimento Aplicações em títulos de curto ou longo prazos; Resgate e liquidação do principal de aplicações; Pgtos. pela aquisição de participações societárias; Recbtos. pela alienação de participações societárias:

Pagamentos por compras de ativos de longo prazo;

Recebimentos de vendas de ativos de longo prazo; Outros recebimentos e pagamentos de investimento.

\section{Fluxo de caixa das atividades operacionais}

Recebimentos de clientes por vendas à vista ou cobranças;

Pagamentos a fornecedores por compras à vista ou a prazo;

Pgtos. de salários, encargos sociais, comissões, férias, etc.;

Pagamentos de aluguéis e fretes;

Pagamentos de juros e encargos de dívidas;

Recebimentos de juros e rendimentos;

Recebimentos de dividendos e juros s/capital próprio;

Pagamentos e antecipações de impostos e contribuições;

Outros recebimentos e pagamentos operacionais.

\section{aros}
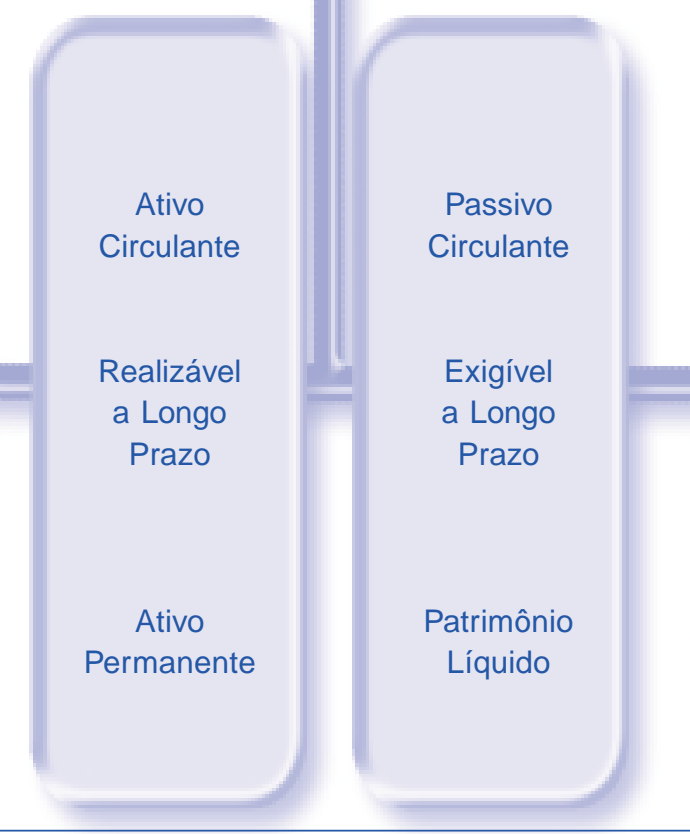

Fluxo de caixa das atividades de financiamento Contratação de empréstimos e financiamentos novos;

Liquidação e pagamentos do principal de dívidas; Produto recebido na emissão de debêntures, assemelhados;

Pagamentos do principal de debêntures e assemelhados;

Pagamentos de dividendos e juros s/capital próprio; Aumento de capital em dinheiro;

Contribuições recebidas para reservas de capital; Compra, reembolso e resgate de ações próprias;

Outros recebimentos e pagamentos de financiamento.
As atividades de financiamento incluem a obtenção de recursos de proprietários e aqueles a eles fornecidos como um retorno sobre, ou um retorno de, seus investimentos; empréstimos de dinheiro e pagamentos dos montantes emprestados ou outra forma de liquidação da obrigação; e a obtenção e pagamento por outros recursos conseguidos de credores por crédito de longo prazo.

As entradas de caixa das atividades de financiamento são: (a) produtos da emissão de instrumentos patrimoniais [títulos]; e (b) produtos da emissão de debêntures, hipotecas, notas e outros empréstimos de curto ou longo prazos.

As saídas de caixa das atividades de financiamento são: (a) pagamentos de dividendos ou outras distribuições aos proprietários, incluindo saídas por readquirir os instrumentos patrimoniais da empresa; (b) pagamentos dos montantes 
emprestados; e (c) outros pagamentos do principal para credores que tenham estendido créditos de longo prazo.

Algumas transações e eventos que causam entradas ou saídas de caixa características das atividades de financiamento são listados abaixo:

- Produtos recebidos da emissão de debêntures e commercial papers;

- Pagamentos de dividendos e juros sobre o capital próprio aos acionistas;

- Produto obtido da colocação de ações novas no mercado;

- Pagamento do principal de empréstimos e financiamentos;

- Contratação de empréstimo bancário de curto prazo e financiamento de longo prazo; e

- Aquisição e alienação de ações em tesouraria.

As atividades de investimento se encontram vinculadas às mudanças da estrutura de investimento da entidade que afetam o caixa, seus ativos, independente do prazo de realização, exceto aquelas de natureza operacional. Conforme parágrafos 15 a 17 do SFAS No. 95:

As atividades de investimento incluem empréstimos efetuados e recebidos e a aquisição ou baixa de instrumentos de endividamento [passivos de outras firmas] ou de patrimônio [participações societárias] e de propriedade, planta, equipamento e outros ativos produtivos, isto é, ativos mantidos para, ou usados na, produção de bens ou serviços pela empresa (que não os materiais que são parte do estoque da firma).

As entradas de caixa das atividades de investimento são: (a) recebimentos de cobranças ou vendas de empréstimos efetuados pela empresa e de outros instrumentos de endividamento (que não equivalentes ao caixa), os quais foram adquiridos pela entidade; (b) recebimentos da venda de investimentos patrimoniais de outras empresas e de retornos de investimento desses instrumentos; e (c) recebimentos da venda de propriedade, planta, equipamento e outros ativos produtivos.

As saídas de caixa das atividades de investimento são: (a) desembolsos por empréstimos feitos pela organização e pagamentos para adquirir instrumentos de endividamento de outras entidades (que não equivalentes ao caixa); (b) pagamentos para comprar investimentos patrimoniais de outras empresas; e (c) pagamentos no momento, logo antes ou depois da compra, para aquisição de propriedade, planta, equipamento e outros ativos produtivos.

Algumas transações e eventos que causam efeitos sobre as atividades de investimento são:

- Aquisição de imobilizado em dinheiro e pagamentos de montantes parcelados;

- Empréstimos concedidos a coligadas e controladas;

- Produto recebido na venda de participações societárias em outras entidades;

- Recebimentos oriundos de venda de ativos de longo prazo;

- Aplicação em títulos e valores mobiliários de curto ou longo prazo; e

- Resgate do principal de títulos mobiliários.

Já as atividades operacionais envolvem as entradas e saídas de caixa necessárias à manutenção das operações da entidade. Em sua quase totalidade refletem o efeito no caixa dos resultados econômicos mostrados na demonstração de resultado (conceito da inclusão, all-inclusive concept), exceto aqueles classificados como não operacionais. Em conformidade com os parágrafos 21 a 23 do SFAS No. 95:

As atividades operacionais incluem todas as transações e outros eventos que não estão definidos como atividades de financiamento ou investimento nos parágrafos 15 a 20. As atividades operacionais geralmente incluem a produção e entrega de bens e fornecimento de serviços. Os fluxos de caixa das atividades operacionais são geralmente os efeitos no caixa de transações e outros eventos que entram na determinação do resultado líquido.

As entradas de caixa das atividades operacionais são: (a) recebimentos de caixa das vendas de bens ou serviços, incluindo recebimentos de cobranças ou vendas de contas e notas a receber, de curto e longo prazos, de clientes surgidas dessas vendas; (b) recebimentos de caixa de retornos sobre empréstimos, outros instrumentos de endividamento de outras entidades, e ações do patrimônio - juros e dividendos; e (c) todos os outros recebimentos de caixa que não provêm de transações definidas como atividades de financiamento ou investimento, 
como os montantes recebidos de questões judiciais; produto do acordo de seguros, exceto para aqueles que são diretamente relacionados às atividades de financiamento e investimento, como da destruição de uma edificação; e restituição de fornecedores.

Saídas de caixa das atividades operacionais são: (a) pagamentos de caixa para aquisição de materiais para manufatura ou bens para revenda, incluindo pagamentos do principal sobre contas e notas a pagar de curto e longo prazos a esses fornecedores de materiais ou bens; (b) pagamentos de caixa para outros fornecedores e empregados por outros bens ou serviços; (c) pagamentos de caixa aos governantes por impostos, taxas, contribuições ou outras multas ou penalidades; (d) pagamentos de caixa para emprestadores e outros credores pelos juros; e (e) todos os outros pagamentos de caixa que não provêm de transações definidas como atividades de investimento e financiamento, como pagamentos para questões judiciais, contribuições em dinheiro para caridade e caixa restituído aos clientes.

Algumas transações e eventos que causam efeitos no caixa das operações são listados abaixo:

- Recebimentos de clientes pelas vendas à vista e cobranças de duplicatas a receber;

- Pagamentos a fornecedores pelas compras à vista e de duplicatas a pagar;

- Pagamentos de aluguéis, salários e encargos sociais;

- Pagamentos e recebimentos de juros (sem incluir o principal);

- Recolhimento de imposto de renda, contribuição social, IPI, ICMS e outros; e

- Recebimentos de dividendos e juros sobre o capital próprio.

Como qualquer outro critério de classificação, este apresenta determinados aspectos até certo ponto polêmicos. Por seguirem o conceito da inclusão (allinclusive concept), os fluxos de caixa integrantes das atividades operacionais refletem o efeito no caixa da quase totalidade dos resultados operacionais divulgados na demonstração de resultado, como vendas, custo das vendas, despesas com vendas e administrativas, e outras despesas e receitas operacionais. Por esse motivo os recebimentos de juros e dividendos, bem como os pagamentos de juros, são também classificados junto a essa atividade. Já os efeitos sobre o caixa dos resultados não operacionais seriam distribuídos entre as atividades de financiamento e investimento. Por exemplo, as indenizações recebidas sobre a perda de imobilizado segurado e o produto recebido da baixa de ativos de longo prazo se enquadrariam junto às atividades de investimento.

Não obstante, classificar juros e dividendos como atividades operacionais ${ }^{5}$ não se coaduna com a literatura de finanças, uma vez que se referem a decisões de financiamento (juros e encargos de linhas de crédito) ou investimento (rendimentos de aplicações em títulos mobiliários e em outras entidades) tomadas pelas empresas. Ainda que os empréstimos sejam utilizados para compra de mercadorias para revenda, houve uma decisão de financiamento que irá acarretar desembolsos futuros do principal e encargos: as saídas de caixa decorrentes daquela decisão. Por outro lado, conceder empréstimos a outras entidades como forma de negócio (instituição financeira) significa, certamente, uma decisão operacional. Receber periodicamente dividendos de controladas decorre de uma decisão de investimento, a aquisição de participação acionária nessas empresas; já receber dividendos como forma de negócio (sociedade de participações) envolve uma decisão operacional. De qualquer modo, as duas visões de classificação podem ser articuladas a partir de um conjunto adicional de informações.

\section{Medidas de Desempenho Obtidas da Demonstração de Fluxos de Caixa}

Da mesma forma que as demais demonstrações, a DFC serve de base para cálculo de muitos indicadores financeiros. As medidas mais importantes encontram-se dispostas em quatro categorias distintas, conforme mostram os quadros seguintes. Nesse sentido, cada categoria pretende atender a um dos quatro objetivos mencionados pelo SFAS № 95 para a DFC.

\footnotetext{
5 Para maiores aprofundamentos, ver NUMBERG, H. \& LARGAY III, J. A . Interest Payments in the Cash Flow Statement. Accounting Horizons, december, 1998, e NURNBERG, Hugo \& LARGAy III, A. J. More Concerns over Cash Flow Reporting Under FASB Statement No. 95. Accounting Horizons, december, 1996.
} 
Na elaboração desses indicadores, o valor do fluxo líquido de caixa gerado pelas operações (FCO) exclui as transações não usuais ${ }^{6}$. Nesse aspecto, dada a importância do FCO no contexto das demais entradas e saídas de caixa, torna-se relevante considerar em separado o impacto de transações não rotineiras que possa conter. Por exemplo, na hipótese de adoção de índices para previsão de fluxos de caixa futuros, a inclusão de recebimentos de indenizações judiciais certamente distorceria os fluxos de caixa contínuos atuais, o que poderia conduzir os investidores a enganos.

\section{Quadro 1: Quocientes de Cobertura de Caixa}

\begin{tabular}{|c|c|}
\hline $\begin{array}{l}\text { Cobertura de juros } \\
\text { com caixa }\end{array}$ & $\begin{aligned} & \text { FCO antes de juros } \\
= & \text { e impostos } / \text { juros }\end{aligned}$ \\
\hline $\begin{array}{l}\text { Cobertura de dívidas } \\
\text { com caixa }\end{array}$ & $\begin{aligned} &(\mathrm{FCO}-\text { dividendo } \\
&\text { total }) / \text { exigível }\end{aligned}$ \\
\hline $\begin{array}{l}\text { Cobertura de } \\
\text { dividendos com caixa }\end{array}$ & $\begin{array}{l}\text { FCO / dividendos } \\
\text { totais }\end{array}$ \\
\hline
\end{tabular}

No que concerne à primeira categoria (Quadro 1), os quocientes de cobertura possibilitam a avaliação da liquidez do empreendimento. $O$ índice de cobertura de juros com caixa deveria complementar o indicador de cobertura de juros tradicional. A relação informa o número de períodos que as saídas de caixa pelos juros ${ }^{7}$ são cobertas pelos fluxos de FCO, excluindo destes os pagamentos de juros e encargos de dívidas, imposto de renda e contribuição social sobre o lucro. Ou seja, o valor de 1,3 equivale a dizer que para cada $R \$$ 1,00 pago em juros, a atividade operacional ajustada gerou $R \$ 1,30$ de caixa livre (houve um excedente de $R \$ 0,30$ no exercício): a cada 0,77 período os pagamentos com juros serão cobertos. Quando comparada ao padrão do setor, a medida indica a capacidade relativa do negócio em atender seus compromissos financeiros.

O quociente de cobertura de juros usual, computado numa base por regime de competência, adota o resultado antes das despesas com juros e impostos $^{8}$ dividido pelas despesas financeiras brutas incorridas. Nesse resultado contábil já se encontram deduzidas despesas não desembolsáveis, como as despesas de depreciação. Por outro lado, considera receitas e despesas ainda não cobradas e pagas. Parte dos juros contabilizados por regime de competência serão pagos oportunamente. Daí esse índice de cobertura contábil dos juros situar-se muito distante da realidade dos fluxos de caixa. Logo, uma medida melhor seria considerar os fluxos de FCO antes de juros e impostos dividido pelos pagamentos de juros realizados no período.

Para a continuidade dos negócios da empresa, é necessário não somente atender ao pagamento dos juros e encargos correntes, mas também quitar o principal das dívidas. Duas medidas potencialmente úteis às instituições financeiras para avaliação da capacidade da entidade em honrar suas obrigações consistem no quociente do fluxo de caixa operacional retido sobre dívidas totais e o índice de fluxo de caixa operacional retido sobre pagamentos de dívidas (principal e encargos). O fluxo de caixa operacional retido (não distribuído) mede o caixa disponível para reinvestimento que foi gerado pelas operações. Pode ser definido como fluxos de FCO exclusive todos os pagamentos de dividendos.

Ambas as relações sinalizam o período de tempo necessário para livrar a companhia de suas obrigações utilizando fluxos de caixa retidos das operações para seu pagamento. O primeiro quociente leva a dívida total em consideração - os passivos circulante e exigível a longo prazo - e, assim, revela o número de anos que, no nível dos fluxos de caixa atuais, seriam necessários para quitar todo o exigível. Por sua vez, o segundo sinaliza se o fluxo de FCO retido tem sido adequado para cumprir os vencimentos das dívidas dentro do exercício.

O quociente de cobertura de dividendos com caixa fornece evidência da capacidade de pagar dividendos preferenciais e ordinários atuais com base no fluxo de FCO normal. Essa medida permite avaliar a

\footnotetext{
6 Integram essas transações os resultados operacionais que não surgem com freqüência e os não operacionais. Podem ser citados os resultados auferidos na alienação de ativo fixo ou participação societária, de recebimento de indenizações por perda de ativos segurados e de recebimentos de subvenções - desde que não registrados como reservas de capital. Na realidade essas transações constituem atividades de investimento ou financiamento.

${ }^{7}$ De modo a evitar distorções, deveriam ser computados apenas os juros reais, com base em relatórios sob correção integral.

${ }^{8}$ No caso brasileiro, imposto de renda e contribuição social sobre o lucro líquido.
} 
habilidade da empresa em pagar todos os dividendos estabelecidos no estatuto social.

Contudo, diversos entendimentos podem surgir quanto ao que considerar como pagamento de dividendos. O conceito empregado depende de que se leve ou não em conta a capacidade de cobrir os dividendos atuais ou futuros, com a inclusão ou não dos juros sobre o capital próprio. Quanto ao primeiro aspecto, se a empresa tem seguido uma política estável na determinação do montante dos dividendos, então o valor corrente pago em dividendos ordinários poderia ser mantido, conforme relatado na DFC. De maneira alternativa, caso os dividendos sejam elevados constantemente ${ }^{9}$, os dividendos totais declarados no presente exercício poderiam ser empregados como uma medida oportuna das saídas de caixa esperadas. Além disso, a fórmula poderia ainda ser ajustada por uma taxa esperada de crescimento dos dividendos com base no histórico da empresa.

Por exemplo, numa situação onde a organização tenha pago $\mathrm{R} \$ 12.000$ em dividendos e seu FCO tenha sido de $R \$ 48.000$, admitindo-se uma taxa de crescimento de $5 \%$ ao ano e mantendo-se o FCO no mesmo nível, então o índice esperado para o próximo período seria de $3,81(R \$ 48.000 /\{R \$ 12.000 \times 1,05\})$.

Já no que diz respeito ao segundo aspecto, a inclusão dos pagamentos de juros sobre o capital próprio seria coerente, porém com as mesmas dificuldades encontradas na situação anterior, o tratamento a ser dispensado na hipótese de crescimento do patrimônio líquido do negócio.

\section{Quadro 2: Quocientes de Qualidade do Resultado}

\begin{tabular}{|c|c|c|}
\hline $\begin{array}{l}\text { Qualidade das } \\
\text { vendas }\end{array}$ & $=$ & $\begin{array}{l}\text { caixa das vendas / } \\
\text { vendas }\end{array}$ \\
\hline $\begin{array}{l}\text { Qualidade do } \\
\text { resultado }\end{array}$ & $=$ & $\begin{array}{l}\text { FCO / resultado } \\
\text { operacional }\end{array}$ \\
\hline $\begin{array}{l}\mathrm{F} \\
\mathrm{re} \\
\mathrm{e}\end{array}$ & \multicolumn{2}{|c|}{$\begin{array}{l}\text { FCO antes de juros e impostos / } \\
\text { resultado antes de juros, impostos } \\
\text { e depreciação }\end{array}$} \\
\hline
\end{tabular}

A segunda categoria (Quadro 2) corresponde aos indicadores de qualidade do resultado. Uma modalidade desse grupo consiste na qualidade caixa das vendas, que mede a proporção das receitas de vendas ${ }^{10}$ convertidas em dinheiro no exercício pelos recebimentos e cobranças de clientes. O problema surge devido ao fato de esta e outras informações se apresentarem nas demonstrações de maneira bastante agregada, o que dificulta sua determinação exata pelo analista externo. O montante dos recebimentos de vendas somente pode ser aproximado $^{11}$ com base nos dados publicados, derivando um índice próximo ao real.

Por sua vez, a abordagem mais simples para avaliação da qualidade do resultado consiste num índice que compara fluxos de FCO ao resultado operacional (lucro ou prejuízo operacional líquido). 0 quociente pretende fornecer uma indicação da dispersão entre os fluxos de caixa e os lucros divulgados. Em condições normais, a medida do lucro inclui receitas (como vendas a prazo ainda não recebidas), custos e despesas (compras de matériasprimas ainda não pagas e depreciações) que não provocam um impacto direto no caixa atual. Essas transações e eventos podem causar diferenças acentuadas entre os montantes de fluxos de caixa e de lucros, as quais podem inclusive realçar variações anormais no quociente ao longo do tempo. Não obstante, ambos tendem a se igualar em momento futuro, por ocasião da descontinuidade das operações do negócio.

Por exemplo, um quociente de 0,7 significa que para cada $R \$ 1,00$ de lucro operacional líquido o empreendimento gerou $\mathrm{R} \$ 0,70$ em caixa operacional. A distância entre os dois valores explica-se pela presença, naquele lucro, daqueles resultados que não afetam o caixa mas, em conformidade com o regime de competência, precisam ser computados.

Uma alternativa de cálculo do indicador qualidade de resultado diz respeito ao fluxo de FCO

\footnotetext{
${ }^{9}$ Pode acontecer de o empreendimento se achar em fase de crescimento, por exemplo. Conforme o modelo de Modigliani e Miler, o valor da empresa não se altera devido à política de dividendos, desde que mantidas as premissas básicas do modelo.

${ }^{10}$ Em termos ideais, a receita operacional bruta, não se incluindo os impostos e contribuições subjacentes no cálculo (ICMS e IPI faturados, Pis e outras contribuições incidentes sobre o faturamento), dado que os recebimentos e cobranças de clientes (numerador) não são deduzidos daqueles pagamentos.

${ }^{11}$ A maior parte das empresas norte-americanas adota o método indireto no cálculo do FCO. Raras são as que divulgam a medida pelo método direto, que mostra o valor exato dos recebimentos de clientes.
} 
antes dos pagamentos de juros e impostos dividido pelo resultado operacional antes das despesas financeiras, com impostos e depreciações ${ }^{12}$. Essa relação elimina alguns dos principais itens que não afetaram o disponível corrente, contidos na demonstração de resultado (depreciação, variações monetárias e cambiais de longo prazo e impostos diferidos), e resulta numa melhor aproximação do caixa ao resultado das operações regulares. Quaisquer variações de tendência expressivas da relação justificariam uma investigação mais acurada.

\section{Quadro 3: Quocientes de Dispêndios de Capital}

$\begin{array}{ll}\begin{array}{l}\text { Aquisições } \\ \text { de capital }\end{array} & \begin{array}{l}\text { (FCO - dividendo total) } \\ \text { investimentos de capital }\end{array} \\ \begin{array}{l}\text { Investimento / } \\ \text { financiamento }\end{array} & \begin{array}{l}\text { fluxo de caixa liq. para } \\ \text { investimentos / fluxo de cainanciamentos }\end{array} \\ \text { e fluxo de caixa líquido para investimentos / fluxo } \\ \text { de caixa líquido de operações e financiamentos }\end{array}$

A terceira categoria (Quadro 3) abrange as medidas de dispêndios de capital ${ }^{13}$. Nesse sentido, o quociente de aquisições de capital sinaliza a habilidade do negócio em atender suas necessidades por dispêndios líquidos de capital (aquisições menos alienações), sendo calculado como fluxos de caixa operacionais retidos divididos pelas aquisições líquidas de ativos produtivos (imobilizado). Utiliza-se o montante dos fluxos de caixa retidos após o pagamento de dividendos como um parâmetro da disponibilidade efetiva de caixa para financiamento daqueles investimentos. Mesmo que os dividendos não sejam pagos no exercício atual em razão de insuficiência financeira temporária, caso o tenham sido no passado, existe uma razoável expectativa de que continuarão a ocorrer. Desse modo, os dividendos pagos (ou esperados) seriam deduzidos dos fluxos de FCO.
Uma questão relevante no cálculo dos quocientes de dispêndios de capital consiste em sua própria definição. Dispêndios de capital poderiam limitar-se à reposição de instalações e equipamentos destinados às operações normais (ativo imobilizado), ou poderiam incluir aquisições de outras divisões operacionais ou companhias (permanente consolidado). Gastos realizados para treinamento de pessoal, pesquisa e desenvolvimento de produtos, e implementação de sistemas de informação em tese representam exemplos de dispêndios genuínos para expansão, mas nem sempre são registrados como ativo permanente diferido da empresa.

Uma outra questão diz respeito a como tratar as alienações desses investimentos. Poderiam ser somadas aos fluxos de caixa retidos ou equiparadas contra dispêndios de capital. Pode-se entender a variação dos ativos produtivos (aquisições menos alienações) como uma forma de manter um retorno satisfatório das atividades operacionais. Os produtos recebidos da alienação seriam então investidos em novos ativos produtivos de modo a atingir aquele nível de atividade desejado. Esses recursos, portanto, poderiam ser incluídos nos fluxos de FCO.

As aquisições mais importantes quase sempre acontecem por financiamento junto a instituições financeiras, o qual não resulta num impacto imediato sobre as saídas de caixa. Logo, os fluxos de caixa para dispêndios de capital podem variar de maneira expressiva em cada exercício, na dependência da política adotada pela companhia. As saídas de caixa futuras decorrentes dessas aquisições ocorrem quando do pagamento do principal (atividade de financiamento), dos juros e dos encargos (atividade operacional). Assim, o impacto total no fluxo de caixa da decisão de aquisição usualmente não aparece como parte das atividades de investimento, salvo nos casos de pagamentos à vista ou a prazo efetuados ao próprio produtor do ativo comprado. Essa dificuldade decorre do critério de classificação empregado pelo SFAS No. 95.

A relação entre os fluxos de caixa operacional, de

\footnotetext{
12 No caso brasileiro, seriam incluídas despesas financeiras líquidas, imposto de renda, contribuição social sobre o lucro líquido, despesas com depreciação, amortização, exaustão e outras contrapartidas de provisionamentos do ativo permanente.

13 Gastos incorridos mas registrados como itens do ativo permanente, os quais contribuirão na formação de resultados (presumivelmente favoráveis) em período futuro. Aquisições de máquinas e equipamentos, fórmulas, patentes de invenção adquiridas, investimentos em P\&D de novos produtos e gastos pré-operacionais constituiriam alguns exemplos de dispêndios de capital.
} 
investimento e de financiamento pode revelar como os investimentos têm sido financiados. A relação investimento e financiamento compara os fluxos líquidos necessários para finalidades de investimento, com aqueles gerados de financiamento. Por outro lado, os fluxos de caixa das atividades de investimento podem ser também comparados aos fluxos de caixa das atividades operacionais. Na prática, essas atividades tendem a flutuar de modo que variações acentuadas sejam verificadas em determinados períodos. Como alternativa, o emprego de valores médios obtidos a partir de uma série de anos seria adequado.

Por exemplo, suponha que em determinado exercício uma entidade haja apurado uma saída líquida de caixa das atividades de investimento da ordem de $\mathrm{R} \$ 120.000$ e uma entrada líquida de financiamento de apenas $R \$ 20.000$. A relação entre as duas atividades corresponderia a 6,0: as atividades de financiamento foram insuficientes para atender às necessidades de caixa de investimento, o que teria levado a empresa a financiar o excedente com caixa das operações. Considere, ainda, que as atividades de financiamento tenham incluído o pagamento de $\mathrm{R} \$ 80.000$ relativo ao principal de uma série de debêntures, embora a entrada líquida média dessa atividade verificada nos anos mais recentes seja de $\mathrm{R} \$ 1$ 100.000. Nessas condições, a relação muda para $1,2(R \$ 120.000 /\{R \$ 20.000+R \$ 80.000\})$ ao se desconsiderar aquela transação eventual.

A quarta categoria (Quadro 4) abrange os indicadores de fluxo de caixa por ação e retorno sobre o investimento. Calcula-se o fluxo de caixa por ação como o caixa disponível aos acionistas ordinários ${ }^{14}$ dividido pelo número médio ponderado de ações ordinárias em circulação. O fluxo de caixa por ação sinaliza o fluxo de caixa operacional atribuível a cada ação ordinária. Os investidores podem determinar o quociente payout de caixa pelo confronto do índice de cobertura de dividendos com caixa ao fluxo de caixa por ação. Além disso, o quociente permite a comparação do caixa total disponível por ação ao caixa distribuído em dividendos - uma medida do potencial de distribuição do negócio.

\section{Quadro 4: Retornos do Fluxo de Caixa}

Fluxo de caixa (FCO - dividendos preferenciais) por ação

$=$ / quantidade de ações ordinárias

$\begin{aligned} & \text { Retorno do caixa } \\ & \text { sobre os ativos }\end{aligned}=\begin{aligned} & \text { FCO antes juros e impostos } \\ & / \text { ativos totais }\end{aligned}$

Retorno sobre passivo FCO/ (patrimônio líquido e patrimônio líquido $=$ + exigível de longo prazo)

Retorno sobre o patrimônio líquido = FCO / patrimônio líquido

Entretanto, o FASB proibiu a exposição dessa medida junto aos relatórios periódicos publicados pelas companhias norte-americanas, conforme expresso no parágrafo 34 do SFAS No.95, por entender que essa prática confundiria os usuários em suas avaliações de desempenho, em especial misturando os regimes de competência (ênfase no lucro por ação) e de caixa:

"As demonstrações financeiras não divulgarão um montante de fluxo de caixa por ação. Nem o fluxo de caixa nem quaisquer de seus componentes é uma alternativa para o resultado líquido como um indicador de desempenho da empresa, como o relato de montantes por ação poderia implicar."

Essa postura não é coerente com seus próprios objetivos. Dentre seus objetivos, o FASB visa a fornecer informações úteis aos usuários das demonstrações financeiras, e informações sobre fluxos de caixa são relevantes para tomada de decisões, inclusive para fins da avaliação de retornos sobre os preços das ações.

Talvez mais atraentes que o quociente fluxo de caixa por ação sejam aqueles ligados à recuperação (retorno) do caixa sobre o investimento. Estes podem ser calculados como um retorno sobre os ativos totais, um retorno sobre o exigível de longo prazo e o patrimônio líquido, ou um retorno sobre o patrimônio dos acionistas apenas.

O retorno de caixa sobre os ativos totais -

\footnotetext{
14 No caso, o fluxo de caixa operacional menos os dividendos fixos aos acionistas preferenciais. Nesses índices não foram deduzidos do fluxo de caixa das operações os investimentos necessários à manutenção do nível corrente de atividade, ou seja, o fluxo de caixa livre disponível para fins de pagamento de dividendos (aos acionistas), baixas de dívidas e outras destinações.
} 
computado numa base caixa antes de impostos e juros - equivale ao retorno sobre o investimento total, a taxa de retorno contábil clássica fundamentada no regime de competência.

Usualmente considerada a relação-chave da lucratividade, sua popularidade e facilidade de aplicação têm contribuído para seu uso até certo ponto indiscriminado, a despeito de suas limitações técnicas. De modo semelhante, a medida de geração de caixa dos ativos também se revela como essencial à avaliação de investimentos. Alterações na base de investimento podem, também, distorcer a medida. Um quociente de 0,25 em determinado ano sinaliza que o investimento empregado (ativo total) foi recuperado em $25 \%$ em termos de disponibilidades nesse período. Em princípio, a comparação dessa taxa àquela real de juros representa um dos critérios para avaliação de desempenho.

O retorno de caixa sobre o capital investido, calculado do ponto de vista do investimento permanente realizado por credores e acionistas exigível a longo prazo e patrimônio líquido - sinaliza o potencial de recuperação de caixa do negócio para esses investidores. Essa medida de retorno do caixa seria melhor formulada antes das distribuições pagas a tais investidores, o que implica o uso de uma base antes dos juros, e mesmo de impostos (ajuste ao numerador).

Por sua vez, o retorno sobre o patrimônio da empresa emprega como denominador o patrimônio líquido da entidade, e mede a taxa de recuperação de caixa dos investimentos realizados pelos acionistas. Assim, o numerador não deve eliminar o efeito do custo do capital de terceiros: os juros e encargos pagos.

Todas essas medidas de retorno de caixa, obtidas numa série histórica e comparadas às médias do setor, fornecem um mínimo de orientação sobre a capacidade do empreendimento em gerar fluxos de caixa futuros.

Em suma, os conjuntos de indicadores expostos auxiliam analistas, credores e outros usuários na previsão de fluxos futuros e medição de desempenho dos fluxos correntes de caixa. Porém, conforme mencionado, sofrem as mesmas limitações ${ }^{15}$ das medidas convencionais, sobretudo quando utilizados de forma isolada e para um período curto de tempo. Em verdade, representam um dos instrumentos disponíveis para acompanhamento da situação financeira das empresas. Ainda assim, a avaliação de tendências, bem como suas comparações às médias setoriais, forneceriam a evidência de suas relevâncias.

\section{Modelo de Análise da CVRD e CEMIG}

Foram utilizados os dados publicados pela Companhia Vale do Rio Doce (CVRD) e pela Centrais Elétricas de Minas Gerais S/A (CEMIG), uma vez que essas empresas apresentaram DFCs completas no conjunto de seus relatórios anuais de 1997 a 1999 com razoável nível de detalhe, dentre aquelas raras que divulgaram esse tipo de informação. Nesse sentido, serão comentados determinados aspectos relativos aos critérios de classificação por atividades adotados por ambas, todavia evitando-se comparar os índices extraídos, haja vista tratar-se de empresas de setores diferentes.

\footnotetext{
15 A exemplo dos fluxos de resultado (regime de competência), os fluxos de caixa (regime de caixa) também são suscetíveis a manipulações. Antecipações de recebimentos e postergações de pagamentos, mesmo danosos ao desempenho de médio e longo prazos do negócio, consistiriam algumas das práticas de window dressing da DFC. Outro problema consiste nas diferenças entre os critérios de classificação adotados pelas empresas, o que dificulta comparações.
} 
TABELA 1: DEMONSTRAÇÃO DE FLUXOS DE CAIXA - CVRD

\begin{tabular}{|c|c|c|c|}
\hline (em milhões de reais) & 1.999 & 1.998 & 1.997 \\
\hline \multicolumn{4}{|l|}{ Fluxos de caixa provenientes das operacões } \\
\hline Lucro líquido do exercício & 1.251 & 1.029 & 756 \\
\hline Ajustes para reconciliar lucro / recursos operações & & & \\
\hline Depreciação, amortização e exaustão & 274 & 262 & 274 \\
\hline Resultado de equivalência patrimonial & (53) & $(133)$ & (122) \\
\hline Imposto de Renda e Contribuição Social diferidos & 153 & 99 & 30 \\
\hline Provisão para contingências & 93 & 55 & 86 \\
\hline Variações monetárias líquidas de ativos e passivos & 768 & 174 & 82 \\
\hline Outros & 37 & 28 & $(104)$ \\
\hline Sub-total & 2.523 & 1.514 & 1.002 \\
\hline \multicolumn{4}{|l|}{ Redução (Aumento) de ativos } \\
\hline Contas a receber de clientes & $(432)$ & $(102)$ & (34) \\
\hline Estoques & (30) & $(60)$ & 44 \\
\hline Outros & 3 & (9) & $(48)$ \\
\hline Sub-total & $(459)$ & $(171)$ & (38) \\
\hline \multicolumn{4}{|l|}{ Aumento (Redução) de passivos } \\
\hline Fornecedores e empreiteiros & 76 & 26 & (9) \\
\hline Salários e encargos sociais & 6 & (27) & (13) \\
\hline Outros & 18 & 39 & 62 \\
\hline Sub-total & 100 & 38 & 40 \\
\hline Recursos líquidos provenientes das operações & 2.164 & 1.381 & 1.004 \\
\hline \multicolumn{4}{|l|}{ Fluxos de caixa utilizados nas atividades de investimento } \\
\hline Depósitos no Bacen - Resolução 432 & - & - & 22 \\
\hline Depósitos a prazo & & & \\
\hline Empréstimos e adiantamentos a ligadas - adições & $(377)$ & $(591)$ & $(298)$ \\
\hline Controladas, coligadas e fundações - baixas & 68 & 330 & 177 \\
\hline Outros & 12 & - & (17) \\
\hline Depósitos e garantias & (28) & $(56)$ & (23) \\
\hline Adições em investimentos & (88) & (21) & (48) \\
\hline Dividendos recebidos & 58 & 74 & 142 \\
\hline Adições de Imobilizado & $(480)$ & $(468)$ & $(454)$ \\
\hline Liquidações de contratos de hedge de ouro & & & 64 \\
\hline Recursos provenientes de alienação de bens do Imobilizado & 1 & 3 & 30 \\
\hline Recursos líquidos utilizados nas ativ. de Investimento & (834) & $(729)$ & $(405)$ \\
\hline \multicolumn{4}{|l|}{ Fluxos de caixa provenientes das ativ. de Financiamento } \\
\hline Empréstimos captados a curto prazo ligadas - adições & 614 & 84 & 481 \\
\hline Controladas, coligadas e fundações - baixas & (324) & (304) & (434) \\
\hline Instituições financeiras & 49 & 37 & 16 \\
\hline Empréstimos e financiamentos captados longo prazo ligadas & 112 & 257 & 127 \\
\hline Instituições financeiras & 430 & 388 & 775 \\
\hline Pagamentos instituições financeiras & $(550)$ & $(404)$ & $(535)$ \\
\hline Juros sobre o capital próprio pagos & $(820)$ & $(705)$ & (324) \\
\hline Ações em tesouraria & & $(45)$ & (28) \\
\hline Recursos líquidos provenientes ativ. de Financiamento & $(489)$ & $(692)$ & 78 \\
\hline Aumento (Redução) do caixa e títulos e valores mobiliários & 841 & $(40)$ & 677 \\
\hline Caixa e títulos e valores mobiliários no início do exercício & 1.068 & 1.108 & 431 \\
\hline Caixa e títulos e valores mobiliários no final do exercício & 1.909 & 1.068 & 1.108 \\
\hline Pagamentos efetuados durante o ano por: & & & \\
\hline Juros & $(201)$ & $(150)$ & (135) \\
\hline Imposto de Renda (no consolidado) & - & - & - \\
\hline Transações que não envolvem o caixa: & & & \\
\hline Conversão de empréstimos e outros em investimentos & 101 & 287 & - \\
\hline
\end{tabular}


Há alguns anos a CVRD vem publicando a DFC como informação adicional junto às demonstrações financeiras integrantes de seu relatório anual. O formato de divulgação empregado pela empresa (Tabela 1) caracterizouse por determinados aspectos. O fluxo de caixa operacional (FCO) foi achado a partir do método indireto ${ }^{16}$, porém com o uso freqüente do termo "Outros", inclusive por valores materiais. Não houve indicação do que essas rubricas abrangiam. Os recebimentos de dividendos foram incluídos junto às atividades de investimento, e não como operacionais conforme a orientação do FASB. Além disso, houve um maior nível de detalhe das atividades de investimento e financiamento em comparação à CEMIG. A CVRD relacionou ao final do relatório informações adicionais sobre o total dos pagamentos de juros e impostos, assim como sobre transações específicas que causarão efeitos nos fluxos de caixa futuros: a conversão de dívidas em ações. Nesse ponto, seguiu a orientação inerente do SFAS № 95.

\footnotetext{
16 Esse método de cálculo do fluxo de caixa das atividades operacionais (FCO) parte do resultado líquido do exercício, como divulgado na demonstração de resultado, até chegar a seu valor após efetuar uma série de ajustes que visam converter o resultado econômico ao fluxo financeiro. Já o método direto forneceria o FCO pelo simples confronto entre entradas e saídas operacionais de caixa.
} 
TABELA 2: DEMONSTRAÇÃO DE FLUXOS DE CAIXA - CEMIG

\begin{tabular}{|c|c|c|c|}
\hline \multicolumn{4}{|l|}{ (em milhões de reais) } \\
\hline \multicolumn{4}{|l|}{ Atividade Operacional } \\
\hline Resultado líquido do exercício & 34 & 483 & 310 \\
\hline \multicolumn{4}{|l|}{ Despesas (Receitas) que não afetam o caixa } \\
\hline Depreciações e amortizações & 448 & 352 & 325 \\
\hline Juros e variações monetárias de longo prazo & 141 & (7) & (68) \\
\hline Imposto de Renda e Contribuição Social diferidos & (11) & (25) & (51) \\
\hline Resultado de Participações societárias & $(6)$ & $(4)$ & 0 \\
\hline Baixa de Imobilizado & 18 & 12 & 18 \\
\hline Provisões para perdas & 49 & 15 & 8 \\
\hline Provisões para créditos de liquidação duvidosa & 34 & 3 & \\
\hline Provisões para contingências & 85 & 2 & \\
\hline Sub-total & 792 & 831 & 542 \\
\hline \multicolumn{4}{|l|}{ Decréscimos (Acréscimos) do Ativo } \\
\hline Consumidores e revendedores & (82) & (75) & (31) \\
\hline Tributos e contribuições sociais compensáveis & (62) & (27) & (18) \\
\hline Devedores duvidosos & 0 & 0 & 24 \\
\hline Almoxarifado & 13 & 18 & 10 \\
\hline Outros ativos circulantes & (39) & 23 & 4 \\
\hline Redução no Realizável a Longo Prazo & 0 & 0 & 128 \\
\hline Títulos e valores mobiliários - longo prazo & 0 & 0 & 0 \\
\hline Contrato de cessão de créditos & 24 & 54 & \\
\hline Títulos de valores mobiliários & 13 & (55) & \\
\hline Outros realizáveis a longo prazo & (16) & 1 & \\
\hline Sub-total & (148) & (61) & 119 \\
\hline \multicolumn{4}{|l|}{ Acréscimos (Decréscimos) do Passivo } \\
\hline Fornecedores e supridores & 40 & 46 & (3) \\
\hline Tributos e Contribuição Social & $(163)$ & 72 & 69 \\
\hline Participação nos lucros & (6) & 18 & (6) \\
\hline Salários e contribuições sociais & 14 & $(28)$ & 15 \\
\hline Encargos do consumidor a recolher & 21 & 4 & (25) \\
\hline \multicolumn{4}{|l|}{ Empréstimos e financiamentos } \\
\hline Outros & (41) & 33 & 99 \\
\hline Sub-total & (66) & 154 & 149 \\
\hline Caixa Gerado (Consumido) pelas Operações & 578 & 924 & 810 \\
\hline \multicolumn{4}{|l|}{ Atividade de Financiamento } \\
\hline Financiamentos obtidos & 50 & 144 & 128 \\
\hline \multicolumn{4}{|l|}{ Empréstimos de curto prazo } \\
\hline Baixa de empréstimos e financiamentos & (350) & $(163)$ & (130) \\
\hline Obrigações especiais - participação financeira consumidores & 98 & 77 & 97 \\
\hline Venda antecipada de energia elétrica & 171 & (61) & (51) \\
\hline Recursos recebidos para aumento de capital & 0 & 17 & 0 \\
\hline Dividendos recebidos de controladas & 0 & 1 & 0 \\
\hline Juros sobre capital próprio e dividendos & $(270)$ & $(548)$ & (129) \\
\hline Sub-total & (32) & $(534)$ & (84) \\
\hline Total do Ingresso de Recursos & 546 & 391 & 727 \\
\hline \multicolumn{4}{|l|}{ Atividade de Investimento } \\
\hline Aquisição de Imobilizado & $(496)$ & $(541)$ & $(667)$ \\
\hline Aumento de Investimentos & (33) & (2) & (5) \\
\hline Aumento de Diferido & $(1)$ & (1) & (1) \\
\hline Sub-total & $(530)$ & $(544)$ & (674) \\
\hline Variação Líquida do Caixa & 15 & (153) & 53 \\
\hline \multicolumn{4}{|l|}{ Demonstracão da Variacão do Caixa } \\
\hline Saldo no início do exercício & 54 & 207 & 154 \\
\hline Saldo no final do exercício & 69 & 54 & 207 \\
\hline Variação Líquida do Caixa & 15 & (153) & 53 \\
\hline
\end{tabular}


A demonstração publicada pela CEMIG (Tabela 2) apresentou o fluxo de caixa operacional obtido também a partir do método indireto, contudo incluiu nos ajustes os acréscimos líquidos em títulos e valores mobiliários de longo prazo (subtraindo no fluxo). Segundo o SFAS No. 95, essa rubrica deveria compor as atividades de investimento, aberta entre novas aplicações em títulos (entradas de caixa) e baixas do principal de aplicações anteriores (saídas). Por sua vez, as atividades de financiamento abrangeram dividendos recebidos de controladas, não considerados como operacionais conforme exige - FASB. Lamentavelmente, as atividades de investimento se encontram bastante agregadas e restritas aos elementos do ativo permanente: aparentemente as atividades de investimento integrantes dos ativos circulante e realizável a longo prazo foram classificadas como operacionais, o que parece explicar o fato de a empresa haver classificado a variação líquida em títulos de longo prazo no FCO. A companhia utilizou termos imprecisos ou vagos, como "recursos" e "outros", o que dificulta suas identificações e confunde o usuário. Ao final da demonstração foi relacionado um fluxo adicional que deriva as movimentações do caixa pela diferença dos saldos inicial e final do caixa. Esse fluxo poderia ser dispensado mediante a integração completa dos três fluxos a esses saldos.

Embora exibam diferenças relativas de classificação, as duas companhias buscaram caminhos próprios na divulgação do relatório, tendoos transmitido a seus usuários por livre iniciativa. Infelizmente essa política de transparência não tem sido acompanhada pela maioria das companhias abertas no país. A Tabela 3 relaciona algumas das medidas de desempenho obtidas a partir de dados contidos na DFC e em outras demonstrações, respeitando-se os critérios peculiares de classificação adotados por ambas as organizações (no caso as controladoras).

TABELA 3: ELEMENTOS PATRIMONIAIS E ÍNDICES DE DESEMPENHO

\begin{tabular}{|c|c|c|c|c|c|c|}
\hline \multirow{2}{*}{$\begin{array}{l}\text { Empresa } \\
\text { Item / Ano }\end{array}$} & \multicolumn{3}{|c|}{ CVRD (R\$ milhões) } & \multicolumn{3}{|c|}{ CEMIG ( $\mathbf{R} \$ \mathrm{mil})$} \\
\hline & 1.997 & 1.998 & 1.999 & 1.997 & 1.998 & 1.999 \\
\hline Fluxo de caixa operacional & 1.004 & 1.381 & 2.164 & 810.306 & 924.265 & 577.984 \\
\hline Fluxo de caixa de financiamento & 78 & $(692)$ & (489) & $(83.728)$ & $(533.658)$ & (32.442) \\
\hline Fluxo de caixa de investimento & $(405)$ & (729) & (834) & $(673.800)$ & (543.951) & $(530.258)$ \\
\hline Dividendos e juros s/ca. próprio pagos & (324) & $(705)$ & (820) & $(128.707)$ & $(547.971)$ & $(270.298)$ \\
\hline Receita operacional líquida & 3.101 & 3.274 & 4.272 & 2.200 .086 & 2.495 .420 & 2.863 .814 \\
\hline Resultado operacional líquido & 822 & 1.134 & 1.408 & 266.086 & 213.090 & $(96.727)$ \\
\hline Ativo total (final) & 13.958 & 14.411 & 16.780 & 11.096 .920 & 11.328 .7531 & 11.470 .945 \\
\hline Número de ações (em 1.000) & 387.212 & 384.900 & 388.559 & 158.809 & 158.999 & 158.999 \\
\hline \multicolumn{7}{|l|}{ Medidas de desempenho } \\
\hline Cobertura de dividendos & 0,32 & 0,51 & 0,38 & 0,16 & 0,59 & 0,47 \\
\hline Fluxo operacional sobre vendas & 0,32 & 0,42 & 0,51 & 0,37 & 0,37 & 0,20 \\
\hline Índice das operações & 1,22 & 1,22 & 1,54 & 3,05 & 4,34 & $(5,98)$ \\
\hline Retorno do fluxo operacional / ativos & 0,07 & 0,10 & 0,13 & 0,07 & 0,08 & 0,05 \\
\hline Fluxo operacional por mil ações & 2,59 & 3,59 & 5,57 & 5,10 & 5,81 & 3,64 \\
\hline Investimento / financiamento & 5,19 & $(1,05)$ & $(1,71)$ & $(8,05)$ & $(1,02)$ & $(16,34)$ \\
\hline
\end{tabular}


A CVRD aumentou sua geração de fluxos de caixa das atividades operacionais no período 1997-99, o que significa que essas atividades contribuíram para a elevação dos níveis de solvência dos negócios da empresa. Já a CEMIG revelou em 1999 declínio na geração de caixa por suas operações. Curiosamente, as atividades de financiamento de ambas consumiram caixa (saída líquida), exceto em 1997 para a CVRD, ocasião em que houve sua geração (entrada líquida). Uma variação significativa ocorreu para a CEMIG, cuja saída líquida dessas atividades cresceu mais de seis vezes de 1997 para 1998, fato explicado pelo expressivo aumento dos pagamentos de dividendos e juros sobre o capital próprio aos acionistas. As saídas líquidas de caixa das atividades de investimento foram sempre presentes, porém enquanto a CVRD as elevou, a CEMIG as reduziu no período.

A CVRD evidenciou em 1997 um índice de fluxos de caixa de investimento sobre financiamento de 5,19, o que quer dizer que os fluxos de caixa usados para investimentos foram mais de cinco vezes superiores àqueles obtidos das atividades de financiamento. No outro ano, e nos dois para a outra companhia, o quociente não adicionou nenhuma informação, uma vez que existiram saídas líquidas das atividades de financiamento (denominador), ao invés de entradas. Só há sentido em sua interpretação quando entradas de financiamento financiam saídas de investimento.

Em termos aparentes não houve necessidade em elevar o nível de endividamento, uma vez que as operações geraram montantes bastante satisfatórios de disponibilidades. Esse excedente financiou as atividades de investimento (as parcelas não cobertas pelas atividades de financiamento), além de proporcionarem um substancial encaixe em tesouraria.

O quociente de cobertura de dividendos - que incluiu também os pagamentos de juros sobre o capital próprio no numerador - assumiu uma tendência crescente para ambas as organizações no período 1997-1998, mas reverteu essa tendência no ano seguinte.

Já o quociente fluxo operacional sobre vendas, que mede a qualidade-caixa da receita operacional líquida (o grau de conversibilidade das vendas líquidas em disponibilidades), assumiu tendência de crescimento para a CVRD, e estabilidade seguida de declínio para a CEMIG. Para esta última, em 1999 algo como apenas $20 \%$ das vendas se convertem em caixa. A medida fluxo operacional sobre resultado operacional permaneceu de início estável em 1,22 para a CVRD, e depois se elevou. Porém cresceu e depois despencou para a CEMIG, fato causado pela presença de prejuízo operacional líquido em 1999.

O retorno do caixa operacional sobre os ativos totais se mostrou relativamente estável para as empresas nos três anos. A maior taxa, de $13 \%(0,13)$, foi verificada para a CVRD em 1999: a base total de investimento da empresa (ativo total) proporcionou um retorno de $13 \%$ em disponibilidades. Além disso, o fluxo de caixa operacional por ação foi apurado numa base de mil ações, a mesma utilizada pelas duas na divulgação de seus lucros por ação. Assim, ambas evidenciaram tendências de crescimento dessa medida no período 1997-1998, que se explica pela forte geração de caixa das respectivas operações: embora haja aumentado o número de ações em circulação, o aumento dos FCO foram mais que proporcionais. Não obstante, enquanto a CVRD revelou índice surpreendente em 1999, a CEMIG exibiu sua pior medida da série.

Não foi objetivo deste estudo aprofundar a análise financeira das duas companhias ou comparar seus desempenhos, mas apenas expor uma metodologia de cálculo e interpretação de índices extraídos da DFC ainda pouco conhecida no Brasil. A decisão dessas organizações em divulgar esta demonstração deve ser valorizada, ao passo que suas iniciativas deveriam ser seguidas por outras entidades, sempre no sentido da melhoria da qualidade da informação contábil transmitida ao mercado.

\section{Conclusões e Recomendações}

$\mathrm{Na}$ presente pesquisa foram mencionados e discutidos alguns dos índices extraídos da demonstração de fluxos de caixa que se acham disponíveis aos investidores, em especial àqueles que relacionam o montante do caixa gerado (ou consumido) das atividades operacionais. Elaborados de modo semelhante aos quocientes convencionais, sofrem as mesmas limitações destes quando utilizados de maneira isolada e para períodos curtos de tempo. A exemplo da taxa de retorno contábil, há também a possibilidade de manipulação das medidas com base no caixa operacional em razão de 
antecipações de recebimentos e/ou postergações de pagamentos associadas a quaisquer das transações e eventos envolvidos.

Embora ainda não possuam tradição e popularidade no Brasil - uma vez que apenas algumas sociedades anônimas abertas por livre iniciativa publicam a demonstração - acredita-se no aumento relativo de interesse por essas medidas após a reformulação esperada para a atual legislação societária. As dificuldades financeiras recentes vivenciadas por expressivo número de empresas no país possivelmente poderiam ter sido antecipadas pela análise de suas taxas de recuperação de caixa. Ou seja, lucratividade não constitui nos dias atuais uma condição suficiente para a continuidade do negócio; há necessidade em se manter um nível adequado de liquidez. Desse modo, a metodologia discutida nesse artigo adiciona informações relevantes àquelas obtidas com a análise tradicional.

Por outro lado, pouco se tem publicado no Brasil acerca das medidas de desempenho de curto prazo. Linhas de pesquisa sobre os problemas inerentes aos critérios de classificação das transações e eventos por atividades, a respeito da adequação dos métodos direto e indireto de cálculo do caixa operacional às necessidades de informação dos investidores, sobre a aproximação ao caixa das operações por outras medidas de desempenho, representam caminhos a serem percorridos no futuro próximo.

\section{REFERÊNCIAS BIBLIOGRÁFICAS}

BAHNSON, Paul R., MILLER, B. W. P. \& BUDGE, P. B.. Nonarticulation in Cash Flow Statements and Implications for Education, Research and Practice. Accounting Horizons, december, 1996.

BEAVER, W.. Alternative Accounting Measures as Predictors of Failure. The Accounting Review, january, 1968.

CARSLAW, Charles A. \& MILLS, John R.. Developing Ratios for Effective Cash Flow Statement Analysis. Journal of Accountancy, november, 1991.

CZYZEWSKI, A. B. \& HICKS, D. W.. Hold Onto Your Cash. Management Accounting, march, 1992.

GIACOMINO, D. E. \& AMIELCO, D. E.. Cash Flows: Another Approach to Ratio Analysis. Journal of Accountancy, march, 1993.

GUP, B. E. \& DUGAN, M. T.. The Cash Flow Statement: The Tip of an Iceberg. Business Horizons, november/december, 1988.

IJIRI, Yuji. Recovery Rate and Cash Flow Accounting. Financial Executive. march, 1980.
KAPLAN, Robert S. Advanced Management Accounting. Prentice Hall Inc, Englewood, New Jersey, first edition, 1992, capítulo 15.

NUMBERG, H. \& LARGAY III, J. A . Interest Payments in the Cash Flow Statement. Accounting Horizons, december, 1998. More Concerns over Cash Flow Reporting Under FASB Statement No. 95. Accounting Horizons, december, 1996.

SANTOS, Ariovaldo \& LUSTOSA, Paulo R.. Juros e dividendos pagos, onde classificá-los na Demonstração dos Fluxos de Caixa?. Caderno Temática Contábil e Balanços, n.39, 1999.

. Demonstração de Fluxos de Caixa: Uma Reflexão sobre a Objetividade (ou a falta de) do Fluxo de Caixa. Boletim IOB, Caderno Temática Contábil e Balanços, n.14, 1999.

Statement of Accounting Financial Standards No. 95. Statement of Cash Flows. Financial Accounting Series. Financial Accounting Standards Board of the Financial Accounting Foundation, november, 1987. 
WALLACE, R. S. and COLLIER, P. A .. The 'Cash' in Cash Flow Statements: A Multi-Country Comparison. Accounting Horizons, december, 1991

WARREN, Carl S. \& REEVE, James M.. Financial
Accounting. South - Westrn College Editor, seventh edition, 1999, capítulo 15.

WHITE, Gerald I., SANDHI, Ashwnpaul, C. \& FRIED, Dov. The Analysis and Uses of Financial Statements. John Wiley \& Sons, second edition, 1997. 